\title{
Non-Neoplastic Intestinal Disorder
}

National Cancer Institute

\section{Source}

National Cancer Institute. Non-Neoplastic Intestinal Disorder. NCI Thesaurus. Code C53500.

A disorder that affects the small or large intestine and is non-neoplastic in nature.

Representative examples include acute appendicitis, colitis, and inflammatory bowel disease. 